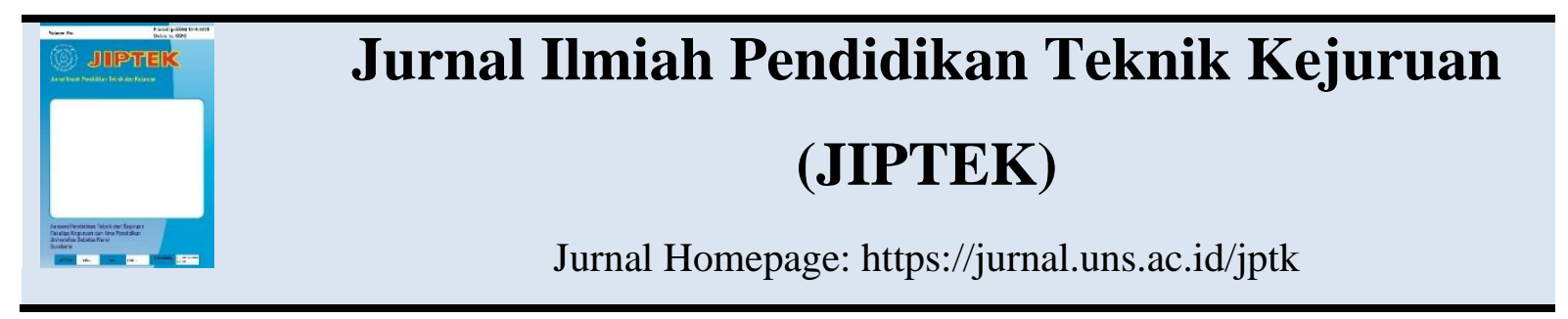

\title{
ANALISIS PENGARUH PEMASANGAN JENIS TURBO CYCLONE \\ DAN INTAKE MANIFOLD MODIFIKASI TERHADAP KONSUMSI BAHAN BAKAR PADA SEPEDA MOTOR KARBURATOR
}

\author{
Bibid Widodo ${ }^{1}$, Husin Bugis ${ }^{2}$ dan Basori ${ }^{3}$ \\ ${ }^{1,2,3}$ Program Studi Pendidikan Teknik Mesin, FKIP, Universitas Sebelas Maret Surakarta \\ Jalan Ahmad Yani 200 Surakarta \\ Email: bi2d.widodo@gmail.com
}

\begin{abstract}
This research aims to know the decrease of fuel consumption on a motorcycle with the installation of turbo cyclone and intake manifold modifications compared with the standard condition. This research is carried out with machine rotation or rotation per minutes (rpm) as control variables, specifically at $1500 \mathrm{rpm}, 4500 \mathrm{rpm}$, and $7500 \mathrm{rpm}$. The methods used in this research is a method of experimentation. The results of this research is the most excellent decline in fuel consumption is while using free vane turbo cyclone with a standard intake manifold with an average decrease of 0.67 $\mathrm{ml} / \mathrm{min}$ or $13.4 \%$ at $1,500 \mathrm{rpm}$, on $4,500 \mathrm{rpm}$ is around $1.5 \mathrm{ml} / \mathrm{min}$ or $11.54 \%$, and at 7,500 rpm is 1.5 $\mathrm{ml} / \mathrm{min}$ or $7.5 \%$. Total fuel consumption decreased is $11 \mathrm{ml} / \mathrm{min}$ or $9.65 \%$ compared with standard conditions.
\end{abstract}

Keywords : turbo cyclone, intake manifold modification, fuel concumtion

\begin{abstract}
ABSTRAK
Penelitian ini bertujuan untuk mengetahui penurunan konsumsi bahan bakar pada sepeda motor dengan pemasangan jenis turbo cyclone dan intake manifold modifikasi dibandingkan dengan kondisi sepeda motor standar. Penelitian dilakukan dengan menggunakan putaran mesin atau rotation per minutes (rpm) sebagai variabel kontrolnya, yaitu pada $1500 \mathrm{rpm}, 4500 \mathrm{rpm}$ dan $7500 \mathrm{rpm}$. Metode yang digunakan dalam penelitian ini adalah metode eksperimen. Hasil dari penelitian ini adalah konsumsi bahan bakar mengalami penurunan paling baik pada saat menggunakan free vane turbo cyclone dengan intake manifold standar dengan rata-rata penurunan sebesar $0,67 \mathrm{ml} / \mathrm{menit}$ atau $13,4 \%$ pada putaran mesin $1.500 \mathrm{rpm}$, pada putaran mesin $4.500 \mathrm{rpm}$ sebesar $1,5 \mathrm{ml} / \mathrm{menit}$ atau $11,54 \%$, dan pada putaran mesin $7.500 \mathrm{rpm}$ sebesar $1,5 \mathrm{ml} /$ menit atau 7,5\%. Dan untuk jumlah total konsumsi bahan bakar mengalami penurunan sebesar $11 \mathrm{ml} /$ menit atau 9,65\% bila dibandingkan dengan kondisi standar.
\end{abstract}

Kata kunci : turbo cyclone, intake manifold modifikasi, konsumsi bahan bakar

\section{PENDAHULUAN}

Salah satu dampak negatif yang ditimbulkan dari meningkatnya jumlah kendaraan bermotor yakni meningkatnya konsumsi bahan bakar. Bahan bakar minyak (BBM) yang bersumber dari fosil merupakan sumberdaya alam yang tidak dapat diperbaharui (unreneweble) dengan 
kata lain apabila dipakai terus-menerus akan menipis dan habis. Meningkatnya konsumsi bahan bakar pada kendaraan bermotor dipengaruhi oleh beberapa faktor antara lain campuran bahan bakar dengan udara yang tidak ideal, tekanan kompresi yang tidak sesuai dengan spesifikasi mesin, nilai oktan bahan bakar yang digunakan rendah, serta pembakaran yang tidak sempurna. Proses pembakaran yang tidak sempurna mengakibatkan tenaga yang dihasilkan oleh ledakan campuran bahan bakar serta udara dalam ruang bakar menjadi tidak maksimal sehingga konsumsi bahan bakar mengalami peningkatan.

Untuk mendapatkan campuran bahan bakar dengan udara yang lebih homogen atau tercampur secara merata dapat dilakukan dengan membuat pusaran udara yang masuk ke dalam karburator ataupun ruang bakar sehingga bahan bakar memiliki kesempatan yang lebih besar untuk bercampur dengan udara dan menjadi lebih merata. Aliran yang berpusar dari campuran bahan bakar dan udara di dalam ruang bakar juga akan mempercepat proses transfer panas. Pencampuran antara campuran yang terbakar dengan yang belum terbakar akan meningkatkan kecepatan pembakaran sehingga konsumsi bahan bakar lebih efisien (Zhang dan Hill dalam Khoir dan Marsudi, 2014: 80). Untuk membuat pusaran udara yang masuk kedalam silinder dapat dilakukan dengan menambahkan peralatan yang mampu mengubah aliran lurus (laminer) udara sebelum masuk ke dalam ruang bakar menjadi aliran pusaran (turbulen) yakni dengan menggunakan turbo cyclone serta memodifikasi saluran masuk bahan bakar (intake manifold).

Menurut Ping Wang dalam Suliyono dan Marsudi (2013: 28) Turbo cyclone adalah alat tambahan yang digunakan pada mesin pembakaran dalam (internal combustion engine) yang berfungsi untuk membuat aliran udara yang akan masuk ke dalam karburator dan silinder ruang bakar menjadi berputar atau swirling. Turbo cyclone ini mirip swirl fan yang sudusudunya tidak berputar (fixed vane) dan ditempatkan pada saluran udara masuk. Berputarnya aliran udara akan meningkatkan efisiensi percampuran bahan bakar dengan udara (fuel/air mixing), meningkatkan intensitas pembakaran dan menstabilkan nyala api pembakaran dengan memanfaatkan zona yang masih dipengaruhi perputaran (internal recirculation zone) serta dapat memperbaiki kecepatan perambatan api sehingga pembakaran yang sempurna dapat dicapai.

Selain pemasangan turbo cyclone untuk meningkatkan campuran bahan bakar dan udara dapat dikakukan dengan memodifikasi saluran masuk bahan bakar (intake manifold). Hal ini dapat dilakukan 
dengan cara membuat alur atau ulir didalam saluran intake manifold. Tujuan dari pembuatan ulir ini adalah untuk merubah laju aliran campuran bahan bakar yang bersifat laminar menjadi turbulen. Dalam aliran turbulen yang terjadi di dalam intake manifold partikel-partikel fluida bergerak dalam lintasan-lintasan yang tidak teratur sehingga membentuk aliran berputar (swirl). Hal tersebut bertujuan untuk mempercepat pencampuran bahan bakar dan udara sehingga pembakaran juga dapat dipercepat.

Penelitian ini melakukan perbandingan antara kendaraan dengan menguunakan jenis turbo cyclone dan intake manifold modifikasi dengan kendaraan standar terhadap konsumsi bahan bakar pada sepeda motor Yamaha Byson $150 \mathrm{cc}$ tahun 2012.

\section{METODE}

\section{A. Rancangan Penelitian}

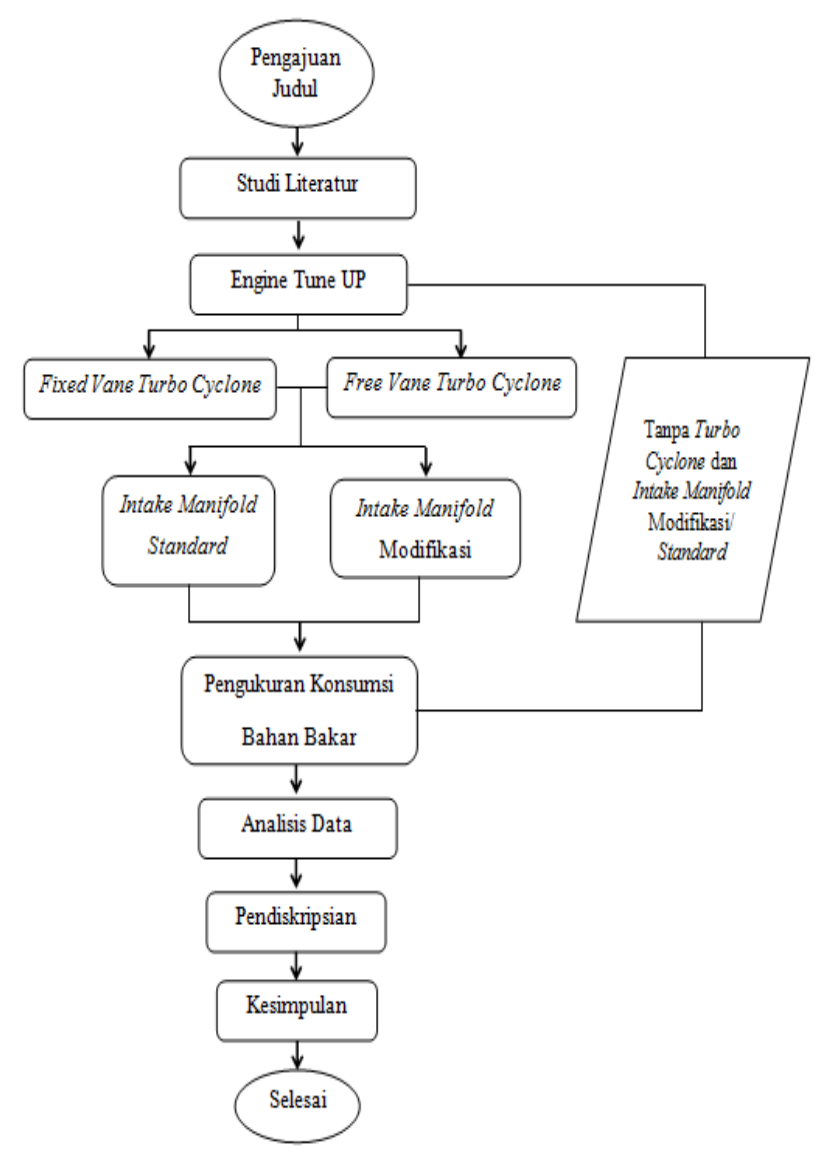

Gambar 1. Rancangan Penelitian

\section{B. Variabel Penelitian}

Variabel bebas dalam penelitian ini adalah jenis turbo cyclone (free vane dan fixed vane), intake manifold modifikasi, dan variasi putaran mesin sepeda motor yakni $1500 \mathrm{rpm}, 4500 \mathrm{rpm}$, serta 7500 
rpm. Variabel terikat dalam penelitian ini adalah konsumsi bahan bakar sepeda motor Yamaha Byson 150 cc Tahun 2012. Dan variabel kontrol dalam enelitian ini adalah Kondisi sepeda motor sesuai standar spesifikasi pabrik, kecuali yang mengalami perlakuan pemasangan turbo cyclone serta intake manifold yang telah dimodifikasi. Bahan bakar pertamax dengan oktan 92 yang dibeli dari SPBU Pertamina. Sudu pada turbo cyclone sesuai dengan standar pabrik. Sistem choke dan komponen lain yang mempengaruhi putaran mesin tidak bekerja. Busi pada sepeda motor sesuai standard pabrik. Selang waktu tiap pengambilan data dibuat selama \pm 10 menit. Penelitian eksperimen ini dilaksanakan di Laboraturium Otomotif Program Pendidikan Teknik Mesin Fakultas Keguruan dan Ilmu Pendidikan Universitas Sebelas Maret Surakarta.

\section{Obyek Penelitian}

Sepeda motor yang digunakan dalam penelitian ini adalah Yamaha Byson 150cc tahun 2012 dengan spesifikasi berikut :

\begin{tabular}{ll} 
Tipe mesin & $\begin{array}{l}\text { 4 Langkah, 2 } \\
\text { Valve SOHC }\end{array}$ \\
\hline Jumlah silinder & $\begin{array}{l}\text { Silinder } \\
\text { Tunggal }\end{array}$ \\
& Udara \\
Sistem & \\
\hline
\end{tabular}

\begin{tabular}{|c|c|}
\hline Volume silinder & $153 \mathrm{cc}$ \\
\hline $\begin{array}{l}\text { Diameter x } \\
\text { langkah }\end{array}$ & $58,0 \times 57,9 \mathrm{~mm}$ \\
\hline $\begin{array}{l}\text { Perbandingan } \\
\text { kompresi }\end{array}$ & $9,5: 1$ \\
\hline $\begin{array}{l}\text { Daya } \\
\text { maksimum }\end{array}$ & $\begin{array}{l}10,1 \mathrm{Kw} / 7.500 \\
\mathrm{rpm}\end{array}$ \\
\hline $\begin{array}{l}\text { Torsi } \\
\text { maksimum }\end{array}$ & $\begin{array}{l}13,6 \mathrm{Nm} / 6.000 \\
\mathrm{rpm}\end{array}$ \\
\hline Sistem starter & $\begin{array}{l}\text { Electric starter } \\
\text { dan kick staeter }\end{array}$ \\
\hline Sistem peluasan & Basah \\
\hline $\begin{array}{l}\text { Kapasitas oli } \\
\text { mesin }\end{array}$ & $\begin{array}{l}\text { Total 1,2 liter, } \\
\text { penggantian } \\
\text { berkala } 1 \text { liter }\end{array}$ \\
\hline $\begin{array}{l}\text { Sistem bahan } \\
\text { bakar }\end{array}$ & $\begin{array}{l}\text { Karburator } \\
\text { BS26 x } 1\end{array}$ \\
\hline
\end{tabular}

\section{Perlengkapan Penelitian}

Perlengkaan yang digunakan dalam penelitian ini yakni sebagai berikut:

1. Tool set adalah alat yang digunakan untuk melepas maupun memasang komponen-komponen yang berada pada mesin kendaraan atau pada penelitian ini untuk melepas dan memasang karburator, turbo cyclone, dan intake manifold.

2. Gelas ukur digunakan untuk mengukur jumlah konsumsi bahan bakar pada sepeda motor yang digunakan sebelum dan sesudah pengujian selama penelitian. 
3. Tachometer adalah alat yang digunakan untuk mengukur besarnya putaran mesin pada saat pengujian dalam pengambilan data

4. Stopwatch adalah alat yang digunakan untuk mengukur waktu. Dalam penelitian ini stopwatch digunakan untuk mengukur lamanya waktu pengukuran konsumsi bahan bakar.

\section{E. Prosedur Pengujian}

Pengujian dilakukan dengan membandingkan antara kendaraan standar dengan kendaraan yang telah mengalami modifikasi atau ekserimen.

\section{Langkah Persiapan Eksperimen}

a. Merancang alat turbo cyclone dan memodifikasi intake manifold.

b. Mempersiapkan alat dan bahan penelitian.

c. Melakukan tune up terhadap bahan penelitian yang akan digunakan yaitu sepeda motor Yamaha Byson 150 cc Tahun 2012.

d. Memasang turbo cyclone dan intake manifold modifikasi pada sepeda motor.

e. Menghubungkan tabung/gelas ukur bensin dengan saluran masuk bahan bakar ke karburator.

f. Menyiapkan tabel data untuk mencatat hasil pengukuran.
2. Langkah Pengukuran Konsumsi Bahan Bakar

a. Mengisi gelas ukur dengan pertamak sebanyak $25 \mathrm{ml}$.

b. Menghidupkan mesin dengan putaran idle.

c. Memutar gas sepeda motor hingga mencapai putaran mesin $1500 \mathrm{rpm}, 4500 \mathrm{rpm}$, dan 7500 rpm secara bertahap selama 1 menit.

d. Mematikan mesin dan mencatat berapa banyak bahan bakar yang dikonsumsi selama 1 menit.

e. Mengulangi langkah pengujian sebanyak 3 kali.

f. Mengulangi langkah pengujian untuk kelompok standar, dan kelompo eksperimen yang menggunakan fixed vane turbo cyclone, free vane turbo cyclone dengan intake manifold standar maupun dengan intake manifold modifikasi.

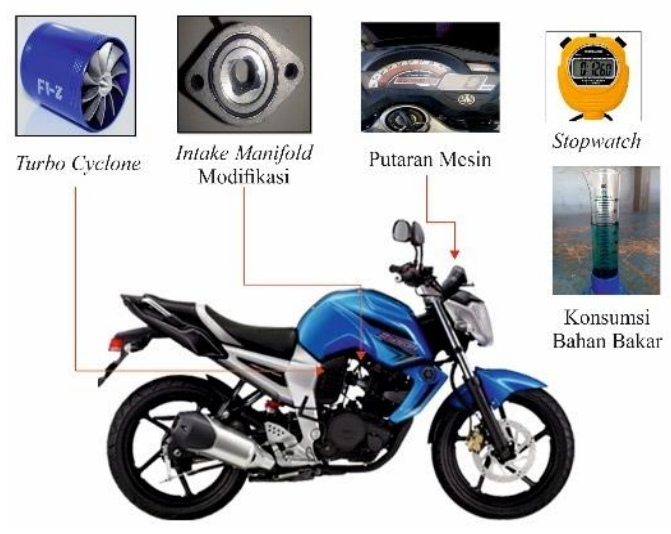

Gambar 2. Skema Pengujian 


\section{F. Teknik Analisis Data}

Penelitian ini merupakan jenis penelitian kuantitatif dengan metode eksperimen. Data yang diperoleh dari eksperimen ini dimasukan dalam tabel, dan ditampilkan dalam bentuk grafik, kemudian dideskripsikan dan dibandingkan antara sepeda motor standar, sepeda motor yang menggunakan turbo cylone, sepeda motor yang menggunakan intake manifold modifikasi serta sepeda motor yang menggunakan turbo cylone dan intake manifold modifikasi. Kemudian ditarik kesimpulan dan diersentasekan dari hasil eksperimen pengukuran konsumsi bahan bakar pada sepeda motor Yamaha Byson $150 \mathrm{cc}$ tahun 2015.

\section{HASIL DAN PEMBAHASAN}

Berdasarkan hasil pengujian diperoleh data konsumsi bahan bakar pada sepeda motor Yamaha Byson 150 cc tahun 2015 sebagai berikut:

\section{Pemasangan Jenis Turbo Cyclone}

Berdasarkan hasil pengujian penggunaan jenis turbo cyclone yang paling efektif dalam penurunan konsumsi bahan bakar pada sepeda motor Yamaha Byson $150 \mathrm{cc}$ tahun 2012 adalah penggunaan turbo cyaclone dengan tipe free vane turbo cylone.
Diamana konsumsi rata-rata pada pemasangan free vane turbo cylone yaitu pada putaran mesin $1.500 \mathrm{rpm}$ sebesar 4,16 $\mathrm{ml} /$ menit, pada putaran mesin $4.500 \mathrm{rpm}$ sebesar 11,16 $\mathrm{ml} /$ menit, dan pada putaran mesin 7.500 rpm sebesar 18,16 ml/menit. Dan jumlah konsumsi total bahan bakar sebebesar $101 \mathrm{ml} /$ menit.

Sementara itu untuk pemasangan turbo cyclone dengan tipe fixed vane turbo cyclone komsumsi rata-ratanya yaitu pada putaran mesin $1.500 \mathrm{rpm}$ sebesar 5,16 $\mathrm{ml} /$ menit, pada putaran mesin $4.500 \mathrm{rpm}$ sebesar $12 \mathrm{ml} / \mathrm{menit}$, dan pada putaran mesin $7.500 \mathrm{rpm}$ sebesar 19,16 ml/menit. Dan jumlah konsumsi total bahan bakar sebebesar $109 \mathrm{ml} / \mathrm{menit}$. Dimana perbandingan konsumsi bahan bakar dari kedua jenis turbo cyclone tersebut dapat dilihat pada diagram dibawah ini:

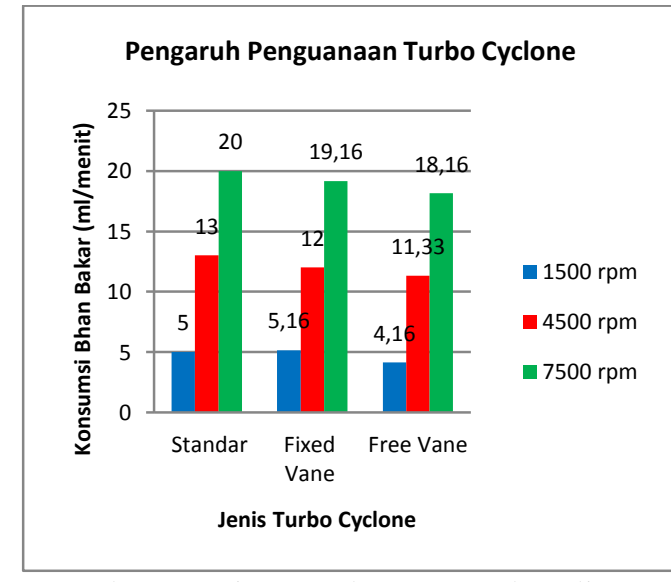

Gambar 3. Diagram batang perbandingan konsumsi bahan bakar menggunakan Fixed Vane Turbo Cyclone dan Free Vane Turbo Cyclone 
Berdasarkan data pada gambar 3 konsumsi rata-rata pemasangan free vane turbo cyclone merupakan jenis turbo cyclone yang paling efektif bila dibandingkan dengan pemasangan fixed vane turbo cyclone dengan penurunan konsumsi sebesar $1 \mathrm{ml} /$ menit atau 19,38\% pada putaran $1.500 \mathrm{rpm}$, kemudian sebesar $0,67 \mathrm{ml} / \mathrm{menit}$ atau $5,58 \%$ pada putaran $4.500 \mathrm{rpm}$, serta penurunan sebesar 1 $\mathrm{ml} / \mathrm{menit}$ atau $5.22 \%$ pada putaran 7.500 rpm.

\section{Pemasangan Intake Manifold}

Berdasarkan data hasil penelitian, penggunaan intake manifold yang paling efektif dalam penurunan konsumsi bahan bakar pada sepeda motor Yamaha Byson 150 cc tahun 2012 adalah penggunaan intake manifold modifikasi. Diamana konsumsi rata-rata pada pemasangan intake manifold modifikasi yaitu pada intake manifold standar komsumsi rata-ratanya yaitu pada putaran mesin $1.500 \mathrm{rpm}$ sebesar 5 $\mathrm{ml} /$ menit, pada putaran mesin $4.500 \mathrm{rpm}$ sebesar $13 \mathrm{ml} / \mathrm{menit}$, dan pada putaran mesin $7.500 \mathrm{rpm}$ sebesar $20 \mathrm{ml} /$ menit. Dan jumlah konsumsi total bahan bakar sebebesar 114 ml/menit. Dimana perbandingan konsumsi bahan bakar dari pemasangan intake manifold standar dengan intake manifold modifikasi dapat dilihat pada diagram dibawah ini:

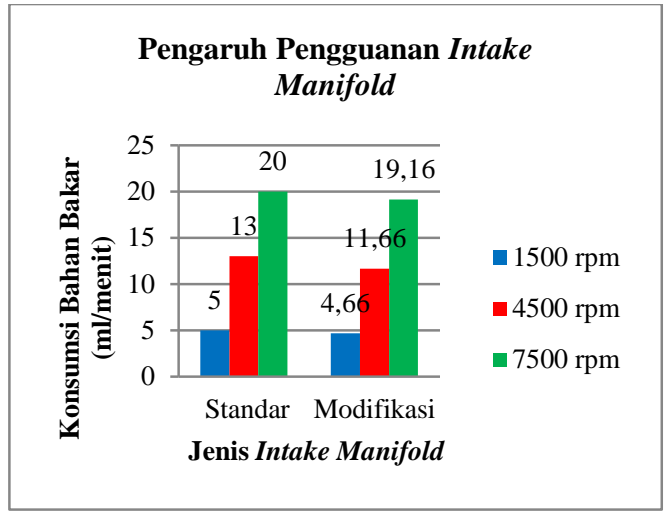

Gambar 4. Diagram batang perbandingan konsmsi bahan bakar menggunakan Intake Manifold Standar dan Modifikasi

Pemasangan intake manifold modifikasi merupakan jenis intake manifold yang paling efektif bila dibandingkan dengan pemasangan intake manifold standar dengan penurunan konsumsi sebesar 0,34 $\mathrm{ml} /$ menit atau $6,8 \%$ pada putaran $1.500 \mathrm{rpm}$, kemudian sebesar 1,34 ml/menit atau 10,31\% pada putaran $4.500 \mathrm{rpm}$, serta penurunan sebesar $0,84 \mathrm{ml} /$ menit atau $4,2 \%$ pada putaran $7.500 \mathrm{rpm}$.

3. Pemasangan Turbo Cyclone dan Intake Manifold Modifikasi

Berdasarkan data hasil penelitian pengaruh pemasangan turbo cyclone dan intake manifold modifikasi terhadap konsumsi bahan bakar pada sepeda motor Yamaha Byson 150 cc tahun 2012 mengakibatkan terjadinya penurunan konsumsi bahan bakar. Diamana konsumsi rata-rata pada pemasangan intake manifold modifikasi yakni pada putaran mesin $1.500 \mathrm{rpm}$ sebesar 4,66 $\mathrm{ml} /$ menit, pada putaran mesin $4.500 \mathrm{rpm}$ 
sebesar 11,66 $\mathrm{ml} / \mathrm{menit}$, dan pada putaran mesin $7.500 \mathrm{rpm}$ sebesar 19,16 ml/menit. Jumlah konsumsi total bahan bakar menggunakan intake manifold modifikasi yakni sebebesar 106,5 ml/menit.

Setelah pemasangan turbo cyclone dan intake manifold modifikasi mengalami penurunan BBM. Berdasarkan data pengujian, konsumsi BBM rata-rata setelah pemasangan free vane turbo cyclone dengan intake manifold modifikasi yakni pada putaran mesin $1.500 \mathrm{rpm}$ sebesar 4,33 ml/menit, pada putaran mesin $4.500 \mathrm{rpm}$ sebesar 11,5 $\mathrm{ml} /$ menit, dan pada putaran mesin 7.500 rpm sebesar 18,5 $\mathrm{ml} /$ menit. Jumlah konsumsi total bahan bakar menggunakan fixed vane turbo cyclone dengan intake manifold modifikasi sebebesar 103 $\mathrm{ml} / \mathrm{menit}$.

Sementara pada pemasngan fixed vane turbo cylone dengan intake manifold modifikasi konsumsi rata-ratanya yakni pada putaran mesin $1.500 \mathrm{rpm}$ sebesar 4,5 $\mathrm{ml} /$ menit, pada putaran mesin $4.500 \mathrm{rpm}$ sebesar 11,5 $\mathrm{ml} /$ menit, dan pada putaran mesin $7.500 \mathrm{rpm}$ sebesar $19 \mathrm{ml} /$ menit. Jumlah konsumsi total bahan bakar menggunakan fixed vane turbo cyclone dengan intake manifold modifikasi sebebesar 105 ml/menit. Dimana perbandingan konsumsi bahan bakar pada pemasangan turbo cyclone dan intake manifold modifikasi dapat dilihat pada grafik dibawah ini:

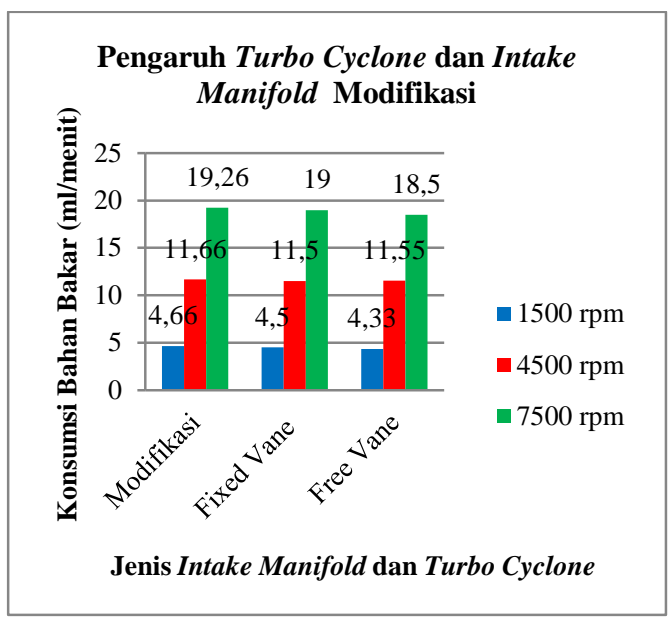

Gambar 5. Diagram batang perbandingan konsumsi bahan bakar menggunakan Intake Manifold Modifikasi dan Turbo Cyclone

\section{PENUTUP}

Berdasarkan hasil penelitian dan analisi data yang dilakukan tentang pengujian konsumsi bahan bakar menggunakan jenis turbo cyclone dan intake manifold modifikasi dapat ditarik kesimpulan sebagai berikut:

1. Pemasangan free vane turbo cyclone merupakan jenis turbo cyclone yang paling efektif terhadap penurunan konsumsi bahan bakar pada sepeda motor Yamaha Byson 150 cc Tahun 2012. Dengan penurunan terbesar yakni $0,84 \mathrm{ml} / \mathrm{menit}$ atau $16,8 \%$ pada putaran mesin $1.500 \mathrm{rpm}$.

2. Pemasangan intake manifold modifikasi merupakan intake manifold yang paling efektif terhadap penurunan konsumsi bahan bakar pada sepeda motor Yamaha Byson 150 cc Tahun 2012. Dengan 
penurunan terbesar yakni $1,34 \mathrm{ml} / \mathrm{menit}$ atau $10,31 \%$ pada putaran mesin 4.500 rpm.

3. Pemasangan jenis free vane turbo cyclone dan intake manifold modifikasi menurunkan konsumsi bahan bakar pada sepeda motor Yamaha Byson 150 ccTahun 2012. Dengan penurunan terbesar yakni $0,67 \mathrm{ml} /$ menit atau $13,4 \%$ pada putaran mesin $1.500 \mathrm{rpm}$.

\section{Implikasi}

Berdasarkan hasil penelitian pengaruh pemasangan jenis turbo cyclone dan intake manifold modifikasi terhadap konsumsi bahan bakar pada sepeda motor dapat diterapkan kedalam beberapa implikasi sebagai berikut:

1. Pemasangan jenis turbo cyclone dan intake manifold modifikasi akan menjadikan laju aliran udara yang masuk kedalam karburator ataupun kedalam mesin yang tadinya sejajar (laminer) berubah menjadi aliran berputar (turbulen) sehingga pencampuran bahan bakar dengan udara semakin optimal dan semakin homogen, sehingga pembakarn menjadi lebih sempurna. Pemasangan turbo cyclone dan intake manifold modifikasi menjadi salah satu upaya positif dalam menurunkan atau penghematan konsumsi bahan bakar pada sepeda motor.
2. Penggunan jenis turbo cyclone dapat di implikasikan pada sepeda motor guna menghemat konsumsi bahan bakar. Jenis free vane turbo cyclone yang paling efektif digunakan untuk penghematan konsumsi bahan bakar pada sepeda motor Yamaha Byson $150 \mathrm{cc}$ tahun 2012.

\section{Saran}

Berdasarkan hasil penelitian yang telah dilakukan pada sepeda motor Yamaha Byson 150 cc Tahun 2012 terdapat saran antara lain:

1. Penelitian lebih lanjut dapat dilakukan pada variabel yang berbeda misalnya pada variasi sudu pada turbo cyclone dan intake manifold modifikasi.

2. Penelitian lebih lanjut dapat dilakukan pada variabel yang sama tetapi pada mesin sepeda motor yang berbeda, yaitu pengaruh terhadap mesin sepeda motor injeksi.

3. Penelitian lebih lanjut dapat dilakuakan dengan menggunakan aplikasi berbasis komputer guna mengetahui usaran udara yang terjadi akibat pemasangan turbo cyclone dan intake manifold modifikasi. 


\section{DAFTAR PUSTAKA}

Al Vandy, R. Muhammad, Aris Triwiyatno, dan Budi Setiyono. 2013. Desain Kontrol Air Fuel Ratio(AFR) pada Model Spark Ignition Engine Dengan Metode Hybrid Fuzzy PI. TRANSIENT, VOL. 2, NO. 2 Juni 2013 ISSN: 2302-9927 halaman 217

Arikunto, Suharsimi.2011. Prosedur Penelitian Suatu Pendekatan Praktik. Jakarta: Rineka Cipta

Khoir, Miftahul dan Marsudi.2014. Pengaruh Penggunaan Turbo Cyclone dan Busi Iridium Terhadap Performa Sepeda Motor Honda Supra X 125 cc Tahun Perakitan 2011. JTM UNESA Volume 02 Nomor 02 halaman 7988

Muchammad.2007. Simulasi Efek Turbo Cyclone terhadap Karakteristik Aliran Udara pada Saluran udara Sepeda Motor 4 Tak 100 CC Menggunakan Computational
Fluid Dynamics. Rotasi Volume 9 Nomor 1 halaman 1-16

Shrirao, Pankaj.N dan Rajeskhumar U. Sambhe.2014. Effect of Swirl Induction by Internally Threaded Inlet Manifolds on Exhaust Emissions of Single Cylinder (DI) Diesel Engine. International Journal of Science and Research (IJSR). Volume 3 Issue 7

Sularto, Tri.2007. Pengaruh Modifikasi Diameter Venturi dan Pemasangan Turbo Cyclone terhadap Daya Mesin pada Sepeda Motor FIZ $R$ 2003. Skripsi dipubikasikan: UNS Surakarta

Suliono dan Marsudi.2013. Pengaruh Penggunaan Turbo Cyclone dan Busi Iridium Terhadap Emisi Gas Buang pada Motor Bensin 4 Tak. JTM UNESA Volume 02 Nomor 02 halaman 27-35 